\title{
LncRNA uc.48+ is involved in the diabetic immune and inflammatory responses mediated by $\mathrm{P}_{2} \mathrm{X}_{7}$ receptor in RAW264.7 macrophages
}

\author{
HONG WU ${ }^{1,2}$, FANG WEN ${ }^{1}$, MEI JIANG ${ }^{1}$, QIANG LIU ${ }^{2}$ and YIJUN NIE ${ }^{1}$ \\ ${ }^{1}$ Department of Clinical Laboratory, First Affiliated Hospital, Medical School of Nanchang University, Nanchang, \\ Jiangxi 330006; ${ }^{2}$ Institute of Blood Transfusion, Jiangxi Province Blood Center, Nanchang, Jiangxi 330077, P.R. China
}

Received November 16, 2017; Accepted April 27, 2018

DOI: 10.3892/ijmm.2018.3661

\begin{abstract}
High glucose combined with high FFAs can contribute to the unfavorable development of type 2 diabetes mellitus (T2DM) and monocytes/macrophages are important in the occurrence and development of T2DM, which is regarded as a type of low-grade inflammation. Although our previous study demonstrated that increased expression of $\mathrm{P} 2 \mathrm{X}_{7}$ receptor $\left(\mathrm{P} 2 \mathrm{X}_{7} \mathrm{R}\right)$ in peripheral blood monocytes may alter the innate immune system and that long non-coding (lnc)RNA uc.48+ was involved in diabetic neuropathic pain, the involvement of uc.48+ mediated by the $\mathrm{P} 2 \mathrm{X}_{7} \mathrm{R}$ in monocyte/macrophages during T2DM has not been reported. In the present study, the effectsof uc.48+ small interference RNA (siRNA) on factors, including the mRNA and protein expression of $\mathrm{P} 2 \mathrm{X}_{7} \mathrm{R}$, apoptosis and proliferation, levels of reactive oxygen species (ROS), cytokine levels, and expression of phosphorylated (p-) extracellular signal-regulated kinase (ERK)1/2, were examined in RAW264.7 macrophages following exposure to high glucose and high plasma free fatty acids (FFAs). After RAW264.7 cells were transfected with uc.48+ siRNA under high glucose conditions and FFAs treatment, the mRNA expression levels of uc.48+ and $\mathrm{P}_{2} \mathrm{X}_{7}$ receptor were detected by reverse transcription-polymerase chain reaction. The protein mass of $\mathrm{P} 2 \mathrm{X}_{7}$ receptor and ERK signaling
\end{abstract}

Correspondence to: Mr. Yijun Nie, Department of Clinical Laboratory, First Affiliated Hospital, Medical School of Nanchang University, 17 Yongwaizheng Street, Nanchang, Jiangxi 330006, P.R. China

E-mail: 570496717@qq.com

Abbreviations: T2DM, type 2 diabetes mellitus; FFAs, high plasma free fatty acids; $\mathrm{P} 2 \mathrm{X}_{7} \mathrm{R}, \mathrm{P} 2 \mathrm{X}_{7}$ receptor; PMA, phorbol myristate acetate; RT-PCR, reverse transcription-polymerase chain reaction; siRNA, small inference RNA; control-siRNA, negative control scrambled siRNA; HG+HF, high glucose combined with high FFAs; ROS, reactive oxygen species; DCFH-DA, 2',7'-dichlorofluorescin diacetate; FITC, fluorescein isothiocyanate; DAPI, 4',6-diamidino-2-phenylindole

Key words: long non-coding RNA uc.48+, immune responses, inflammatory responses, $\mathrm{P}_{2} \mathrm{X}_{7}$ receptor, RAW264.7 macrophages pathway were assessed by western blotting. ROS and calcium concentrations, and culture supernatant cytokine content [tumor necrosis factor- $\alpha$, interleukin (IL)-10, IL-1 $\beta$ ] were detected by fluorescent probes and ELISA respectively. Cell viability and apoptosis were determined by MTS test and flow cytometry, respectively. It was found that treatment of RAW264.7 cells with high glucose and FFAs, which exhibited increased expression of uc.48+, evoked $\mathrm{P} 2 \mathrm{X}_{7} \mathrm{R}$-mediated immune and inflammatory responses through several means, including cytokine secretion, ROS formation, and activation of the ERK signaling pathway. The uc.48+ siRNA regulated these factors and thus influenced the course and outcome of the immune and inflammatory responses mediated by $\mathrm{P} 2 \mathrm{X}_{7} \mathrm{R}$.

\section{Introduction}

The majority of patients with type 2 diabetes mellitus (T2DM) have the characteristics of high blood lipids in addition to high glucose $(1,2)$. High plasma free fatty acids (FFAs) are associated with insulin resistance, inflammation and oxidative stress, which are a result of advanced diabetes mellitus (3). Therefore, high glucose combined with high FFAs can contribute to the unfavorable development of T2DM. By contrast, monocytes/macrophages are important in the occurrence and development of T2DM, which is regarded as a type of low-grade inflammation $(4,5)$. In our previous study, it was demonstrated that the increased expression of $\mathrm{P} 2 \mathrm{X}_{7}$ receptor $\left(\mathrm{P} 2 \mathrm{X}_{7} \mathrm{R}\right)$ in peripheral blood monocytes may alter the innate immune system, contributing to the development of T2DM (6). The high plasma FFA levels in the inflammatory condition of T2DM may result in the continuous secretion of intracellular ATP, which causes the accumulation of extracellular ATP (7). Overstimulation of the $\mathrm{P} 2 \mathrm{X}_{7} \mathrm{R}$ by increasing levels of extracellular ATP may induce uncontrolled $\mathrm{Ca}^{2+}$ influx and activate the release of mature cytokines, including interleukin (IL)-1 $\beta$, IL-18 and tumor necrosis factor (TNF)- $\alpha(8,9)$.

Transcriptome analysis has revealed that only $1-2 \%$ of the human gene encodes protein and the remaining $98 \%$ of the human gene is non-coding RNA $(10,11)$. Long non-coding RNAs (lncRNAs) represent a subgroup of non-coding RNAs, which are $>200$ nucleotides in length and lack the ability to encode proteins (10). Studies have shown that IncRNAs 
regulate various biological processes, including the expression of genesin epigenetics at the transcription and post-transcription levels (12) and they are involved in the regulation of apoptosis, proliferation and differentiation (13). In previous years, studies have identified several hundred lncRNAs characterized with absolute conservation (100\% homology with no insertions or deletions) in the human, mouse and rat genomes $(14,15)$. These conserved lncRNAs have been named ultra conserved RNA (ucRNA). The uc.48+ is one identified lncRNA (http://genome. ucsc.edu). Although our previous preliminary results revealed that lncRNA uc.48+ was involved in diabetic neuropathic pain (16), the role of uc.48+ in monocyte/macrophages has not been reported. Therefore, the present study focused on the role of uc.48+ and its possible mechanism in high glucose and FFA-induced immune and inflammatory responses mediated by $\mathrm{P} 2 \mathrm{X}_{7} \mathrm{R}$ in RAW264.7 macrophages.

\section{Materials and methods}

Individuals and serum RNA isolation. A total of 20 healthy subjects were enrolled from the Blood Center of Jiangxi Province (Nanchang, China). In addition, 38 patients fulfilling the American Diabetes Association diagnostic criteria for T2DM, including 20 patients with normal C-reactive protein (CRP) and 18 patients with high CRP, were recruited from the First Affiliated Hospital of Nanchang University (Nanchang, China). The present study was approved by the local Ethics Committee of from the First Affiliated Hospital of Nanchang University (approval no. 2018 16), and written informed consent was obtained from each individual.

The participant recruitment/samples were collected between June 1, 2014 and August 31, 2014. Blood samples obtained from all individuals were collected and allowed to coagulate for $30 \mathrm{~min}$ at room temperature, followed by centrifugation for $10 \mathrm{~min}$ at $1,300 \mathrm{x} \mathrm{g}$ at $4^{\circ} \mathrm{C}$. The collected sera were centrifuged for another $10 \mathrm{~min}$ at $3,000 \mathrm{x}$ g at $4^{\circ} \mathrm{C}$ to remove any remaining cellular components, divided into $500-\mu 1$ aliquots, and stored immediately at $-80^{\circ} \mathrm{C}$.

Cell culture exposure to high glucose and FFAs. The RAW 264.7 murine macrophage-like cell line was purchased from the Type Culture Collection of the Chinese Academy of Sciences (Shanghai, China). The cells were cultured in DMEM medium (low glucose; Gibco; Thermo Fisher Scientific, Inc. Waltham, MA, USA; cat. no. 11885092) containing $10 \%$ fetal bovine serum (FBS; Hyclone; GE Healthcare Life Sciences, Logan, UT, USA), $100 \mathrm{U} / \mathrm{ml}$ penicillin, and $100 \mathrm{mg} / \mathrm{ml}$ streptomycin sulphate at $37^{\circ} \mathrm{C}$ in a humidified atmosphere containing $5 \% \mathrm{CO}_{2}$. Based on a previous report, the treatment doses of high glucose (17) and high FFAs (18) were 44.4 and $1.0 \mathrm{mM}$, respectively, throughout the study.

$u c .48+$ siRNA treatment. The siRNA specific for uc.48+ was purchased from Invitrogen; Thermo Fisher Scientific, Inc., with the target sequence of 5'-GGCACTACTACTTGCAGAA-3'. The siRNA oligonucleotides that specifically targeted uc.48+ were used in this experiment (16). The uc.48+ was knocked down by RNA interference using Entranster ${ }^{\mathrm{TM}}$ RNA transfection reagent. According to the manufacturer's protocol of the transfection reagent (Engreen Biosystem Co., Ltd. Beijing, China), the uc.48+ siRNA injection at a final concentration of $20 \mathrm{mM}$ was used for subsequent experiments.

Cell treatment and experimental groups. The RAW264.7 macrophages were treated under control [5.5 mM glucose $+1 \%$ bovine serum albumin (BSA; Zhejiang Tianhang Biotechnology Co., Ltd. Hangzhou, China], high glucose and high FFA (44.4 and $1.0 \mathrm{mM}$, respectively) conditions for 3 days. RNA was isolated following treatment in the presence of uc.48+ siRNA or scramble siRNA for $48 \mathrm{~h}$. The other experiment assays (western blot, cell viability and apoptosis assays, and measurement of ROS) were performed following treatment in the presence of uc.48+ siRNA or scramble siRNA for $72 \mathrm{~h}$. The supernatants were stored at $-80^{\circ} \mathrm{C}$ for the enzyme-linked immunosorbent assay. For experiments, the four following groups were assigned: Control group, high glucose and FFA treatment (HGHF) group, uc.48+ siRNA vector-treated $\mathrm{HGHF}$ group $(\mathrm{HGHF}+\mathrm{uc} .48+\mathrm{si})$, and scramble siRNA vector-treated HGHF group ( $\mathrm{HGHF}+\mathrm{NC}$ si).

Serum RNA and total RNA isolation, and reverse transcription-polymerase chain reaction $(R T-P C R)$ analysis. Serum RNA was isolated from the serum using RNA pure Circulating Reagent (CWBIO, Beijing, China; cat. no. CW2281), with modifications. Briefly, $300 \mu \mathrm{l}$ of serum was added to three volumes of RNA pure Circulating Reagent, mixed thoroughly by vortexing and left to stand at room temperature for $5 \mathrm{~min}$. Subsequently, one-fifth of the volume of chloroform was added and shaken vigorously for $30 \mathrm{sec}$, incubated for $5 \mathrm{~min}$ at room temperature, and then centrifuged for $20 \mathrm{~min}$ at $12,000 \mathrm{x} \mathrm{g}$ at $4^{\circ} \mathrm{C}$. The upper aqueous phase was transferred into a new collection tube and one volume of isopropanol was added, mixed thoroughly for $30 \mathrm{~min}$ at room temperature, and centrifuged for $20 \mathrm{~min}$ at $12,000 \mathrm{x}$ at $4^{\circ} \mathrm{C}$. The precipitate was washed twice with $1 \mathrm{ml}$ of $75 \%$ ethanol (diluted with DEPC water). The RNA was eluted by $20 \mu \mathrm{l}$ of RNase-free water. The RAW264.7 macrophages were treated with the control, high glucose and high FFA conditions in the presence of uc.48+ siRNA or scramble siRNA for $48 \mathrm{~h}$. Total RNA was isolated using TRIzol (Invitrogen; Thermo Fisher Scientific, Inc.), according to the manufacturer's protocol. The quality of the RNA was profiled using NanoDrop 2000 spectrophotometer (Thermo Fisher Scientific, Inc.).

RNA was used to synthesize cDNA in $20 \mu \mathrm{l}$ reactions containing $500 \mathrm{ng}$ of DNase-treated RNA, $200 \mathrm{ng}$ of random hexamers, $100 \mathrm{U}$ of Revert Aid reverse transcriptase and 8 units of RiboLock RNase Inhibitor using a Revert Aid First Strand cDNA Synthesis kit (Fermentas; Thermo Fisher Scientific, Inc.). The reaction samples were incubated for $10 \mathrm{~min}$ at $25^{\circ} \mathrm{C}$ and $60 \mathrm{~min}$ at $42^{\circ} \mathrm{C}$, followed by enzyme inactivation for $10 \mathrm{~min}$ at $70^{\circ} \mathrm{C}$ and storage at $-20^{\circ} \mathrm{C}$ until use. In the serum experiments, PCR amplification of the uc.48+ and GAPDH (internal standard for quantification) was performed according to our previously described method (19). A total of $2 \mu \mathrm{l}$ cDNA was amplified in $12.5 \mu \mathrm{l}$ of PCR mixture (Tiangen Biotech Co., Ltd. Beijing, China), $2 \mu 1$ primers ( $1 \mu 1$ sense primer and $1 \mu 1$ antisense primer) and $8.5 \mu \mathrm{l}$ nuclease-free water. The oligonucleotides used to amplify the uc.48+ and GAPDH were as follows: uc.48+, sense 5'-GCAAACTGGATGAGGAT-3' and antisense 5'-GTAGTGCCACAAGGAGA-3', and GAPDH, sense 5'-CAG GGCTGCTTTTAACTCTGGT-3' and antisense 5'-GATTTT 
GGAGGGATCTCGCT-3'. The length of the PCR product was $231 \mathrm{bp}$ for uc.48+ and $199 \mathrm{bp}$ for GAPDH. The PCR conditions of uc.48+ and GAPDH included a hot start at $94^{\circ} \mathrm{C}$ for $3 \mathrm{~min}$, $45 \mathrm{sec}$ denaturation $\left(94^{\circ} \mathrm{C}\right), 45 \mathrm{sec}$ annealing $\left(57^{\circ} \mathrm{C}\right)$, and $45 \mathrm{sec}$ extension $\left(72^{\circ} \mathrm{C}\right)$ for 36 (uc. $48+$ ) or $32(\mathrm{GAPDH})$ amplification cycles, and a final 5 -min extension at $72^{\circ} \mathrm{C}$.

In the RAW264.7 cell experiment, the PCR amplification of the $\mathrm{P} 2 \mathrm{X}_{7} \mathrm{R}$ and $\beta$-actin (internal standard for quantification) was performed according to our previous method using oligonucleotides as described previously (16). A total of $2 \mu 1$ cDNA was amplified in $12.5 \mu \mathrm{l}$ PCR mixture (Tiangen Biotech Co., Ltd.), $2 \mu \mathrm{l}$ primers ( $1 \mu \mathrm{l}$ sense primer and $1 \mu \mathrm{l}$ antisense primer) and $8.5 \mu \mathrm{l}$ nuclease-free water. The following primers were used for PCR analysis: P2X $\mathrm{X}_{7} \mathrm{R}(171 \mathrm{bp})$, sense 5'-GCA CGAATTATGGCACCGTC-3' and antisense 5'-CCCCAC CCTCTGTGACATTC-3'; uc.48+ (231 bp), sense 5'-GCAAAC TGGATGAGGAT-3' and antisense 5'-GTAGTGCCACAA GGAGA-3'; $\beta$-actin, (240 bp), sense 5'-TAAAGACCTCTA TGCCAACACAGT-3' and antisense 5'-CACGATGGAGGG GCCGGACTCATC-3'. The PCR conditions of uc. $48+, \mathrm{P}_{2} \mathrm{X}_{7} \mathrm{R}$ and $\beta$-actin included a hot start at $94^{\circ} \mathrm{C}$ for $3 \mathrm{~min}, 45 \mathrm{sec}$ denaturation $\left(94^{\circ} \mathrm{C}\right), 45 \mathrm{sec}$ annealing $\left(57^{\circ} \mathrm{C}\right.$ for uc. $48+$ and $\beta$-actin; $59^{\circ} \mathrm{C}$ for $\mathrm{P} 2 \mathrm{X}_{7} \mathrm{R}$ ), and $45 \mathrm{sec}$ extension $\left(72^{\circ} \mathrm{C}\right.$ ) for 36 (uc. $48+$ and $\left.\mathrm{P} 2 \mathrm{X}_{7} \mathrm{R}\right)$ or 32 amplification cycles ( $\beta$-actin) and a 5 -min final extension at $72^{\circ} \mathrm{C}$.

The PCR products were run on $1.5 \%$ agarose gels with EB using standard protocols. Densitometric analysis of three different observations was performed using Image-Pro Plus software (version 6.0, Media Cybernetics, Inc., Rockville, MD, USA). In the experiments involving patient serum samples, the results are expressed as the ratio of the uc.48+ band intensity/GAPDH band intensity. In the RAW264.7 cell experiments, the results are showed as the ratio of uc.48+ or $\mathrm{P} 2 \mathrm{X}_{7} \mathrm{R}$ band intensity to $\beta$-actin band intensity.

Western blot analysis. The cells were washed twice with ice-cold PBS and harvested. The lysates were obtained using RIPA buffer containing a protease/phosphatase inhibitor mixture (diluted 1:100, Vazyme Biotech, Nanjing China) and then subjected to $10,000 \mathrm{x}$ g centrifugation at $4^{\circ} \mathrm{C}$ for $20 \mathrm{~min}$. Total protein concentrations in the supernatant were determined using a bicinchoninic acid assay (Beyotime Institute of Biotechnology, Haimen, China). A total of $30 \mu \mathrm{g}$ protein was separated by $6 \%$ sodium deodecylsulfate-polyacrylamide gel electrophoresis, which was then transferred onto polyvinyl difluoride membranes (Millipore, Bedford, MA, USA) by electroblotting. Following blocking with 5\% BSA at room temperature for $2 \mathrm{~h}$, the blots were incubated with the following primary antibodies: $\mathrm{P} 2 \mathrm{X}_{7} \mathrm{R}$ (diluted 1:800, cat. no. ab229453, Abcam, Cambridge, MA, USA), extracellular signal-regulated kinase (ERK)1/2 and phosphorylated (p-)ERK (diluted 1:1,000, cat. no. 5013 and 8544, respectively, Cell Signaling Technology, Inc., Danvers, MA, USA); $\beta$-actin (diluted 1:1,500, cat. no. TA09, Beijing Zhongshan Biotech Co, Ltd., Beijing, China) overnight at $4^{\circ} \mathrm{C}$ and developed with appropriate horseradish peroxidase-conjugated secondary antibodies (diluted 1:2,000, cat. no. ZDR-5306 and ZDR-5307, Beijing Zhongshan Biotech Co., Ltd.) at room temperature for $60 \mathrm{~min}$. An enhanced chemiluminescence kit (SuperSignal West Pico; Thermo Fisher Scientific, Inc.) was used to produce chemiluminescent signals, which were recorded by a Chemi Doc ${ }^{\mathrm{TM}}$ XRS Imaging system (Bio-Rad Laboratories, Inc., Hercules, CA, USA). Band intensity was quantified using Image Pro-Plus software (version 6.0). Protein expression levels are represented as densitometric ratios of the targeted protein relative to $\beta$-actin or ERK1/2.

Analysis of cell proliferation and apoptosis. Cell viability was determined using a 3-(4,5-dimethylthiazol-2-yl)-5-(3-car boxymethoxyphenyl)-2-(4-sulfophenyl)-2H-tetrazolium, inner salt (MTS) assay. The RAW264.7 macrophages were plated in 48 -well plates at a concentration of $2 \times 10^{5}$ cells/well. At $72 \mathrm{~h}$ post-transfection, the media from the control and high glucose- or high FFA-treated cultures were discarded and $200 \mu 1$ of MTS (Promega Corporation, Madison, WI, USA) was added to each well. The cells were incubated for $1-2 \mathrm{~h}$ at $37^{\circ} \mathrm{C}$, following which the cell solution was measured in a microplate reader (RT-6000; Rayto, Shengzhen, China) at $490 \mathrm{~nm}$. All experiments were performed in triplicate.

At $72 \mathrm{~h}$ post-transfection, the cells were harvested and washed three times with PBS, $5 \mu \mathrm{l}$ of Annexin V-FITC and $5 \mu \mathrm{l}$ of PI solution were added and the cells were stained for $15 \mathrm{~min}$ in the dark using the Annexin V-FITC Apoptosis Detection kit (KeyGEN Biotech Co., Ltd., Nanjing, China). The relative percentage of Annexin V-FITC-positive/PI-negative cells was analyzed by flow cytometry (Beckman Coulter, Inc., Brea, CA, USA).

Measurement of ROS. Levels of ROS were measured with 2'7'-dichlorofluorescin diacetate (DCFH-DA) according to the manufacturer's protocol. Briefly, the RAW264.7 macrophages were treated in 24-well dishes and then loaded with DCFH-DA and incubated under the indicated conditions. Aliquots of cell suspensions were centrifuged for $6 \mathrm{~min}$ at $6,000 \mathrm{x}$ g at $4{ }^{\circ} \mathrm{C}$ and added to a cuvette on a spectrofluorometer (Perkin-Elmer, Inc., Waltham, MA, USA). The fluorescence generated by DCFH-DA was monitored and recorded by ratio fluorometry with an emission wavelength of 525 at $488 \mathrm{~nm}$ excitation wavelengths.

Enzyme-linked immunosorbent assay (ELISA). The levels of IL-10, IL-1 $\beta$, and TNF- $\alpha$ were assessed in supernatants collected from RAW264.7 macrophages using specific ELISA kits (Boster Biological Technology, Wuhan, China). The cat. nos. of theIL-10, IL-1 $\beta$ and TNF- $\alpha$ kits were EK0417, EK0394, and EK0527, respectively, which were used according to the manufacturer's protocol.

Statistical analysis. All experiments were performed in triplicate to ensure the accuracy of the results, and data are presented as the mean \pm standard deviation. The data from the cell experiments were normalized by the control group. Statistical analyses were performed using the Statistical Package for Social Sciences (SPSS) 11.5 software (SPSS, Inc., Chicago, IL, USA). Statistical significance was determined by one-way analysis of variance. $\mathrm{P}<0.05$ was considered to indicate a statistically significant difference.

\section{Results}

Anthropometric data, serum biochemistry parameters and serum expression of uc.48+ in healthy subjects and patients 
Table I. Anthropometric data and serum biochemical detection in healthy subjects and patients with T2DM.

Patients with T2DM

\begin{tabular}{|c|c|c|c|}
\hline \multirow[b]{2}{*}{ Parameter } & \multirow[b]{2}{*}{ Healthy subjects } & \\
\hline & & Normal CRP & High CRP \\
\hline Number of patients (female/male) & $20(10 / 10)$ & $20(9 / 11)$ & $18(8 / 10)$ \\
\hline Weight (kg) & $65.30 \pm 8.36$ & $68.17 \pm 5.63$ & $61.29 \pm 7.23$ \\
\hline Age (years) & $41.70 \pm 8.27$ & $47.67 \pm 7.06$ & $52.43 \pm 5.34$ \\
\hline $\mathrm{CRP}(\mathrm{mg} / \mathrm{l})$ & $1.57 \pm 0.43$ & $2.46 \pm 0.28$ & $8.17 \pm 2.95^{\mathrm{a}, \mathrm{b}}$ \\
\hline FPG (mmol/l) & $4.60 \pm 0.55$ & $10.01 \pm 3.92^{\mathrm{a}}$ & $9.89 \pm 2.14^{\mathrm{a}}$ \\
\hline PPG (mmol/l) & $6.52 \pm 0.59$ & $14.18 \pm 4.06^{\mathrm{a}}$ & $13.86 \pm 2.62^{\circ}$ \\
\hline FPI (mIU/l) & $5.88 \pm 1.34$ & $6.12 \pm 1.52$ & $8.73 \pm 1.83^{\mathrm{a}, \mathrm{b}}$ \\
\hline HOMA-IR & $1.20 \pm 0.18$ & $2.72 \pm 0.32^{\mathrm{a}}$ & $3.84 \pm 0.46^{\mathrm{a}, \mathrm{b}}$ \\
\hline Glycosylated serum protein $(\mathrm{mmol} / \mathrm{l})$ & $1.47 \pm 0.38$ & $3.36 \pm 3.43^{\mathrm{a}}$ & $3.93 \pm 3.38^{\mathrm{a}}$ \\
\hline $\mathrm{TG}(\mathrm{mmol} / \mathrm{l})$ & $1.13 \pm 0.38$ & $1.67 \pm 0.61^{\mathrm{a}}$ & $1.72 \pm 0.89^{\mathrm{a}}$ \\
\hline $\mathrm{TC}(\mathrm{mmol} / \mathrm{l})$ & $3.96 \pm 0.68$ & $5.83 \pm 1.38^{\mathrm{a}}$ & $5.71 \pm 0.91^{\mathrm{a}}$ \\
\hline $\mathrm{HDL}(\mathrm{mmol} / \mathrm{l})$ & $1.28 \pm 0.13$ & $1.14 \pm 0.48$ & $1.13 \pm 0.12$ \\
\hline $\mathrm{LDL}(\mathrm{mmol} / \mathrm{l})$ & $2.71 \pm 1.12$ & $3.38 \pm 1.81$ & $3.07 \pm 1.52$ \\
\hline
\end{tabular}

${ }^{\mathrm{a}} \mathrm{P}<0.05$, compared with healthy subjects; ${ }^{\mathrm{b}} \mathrm{P}<0.05$, compared with patients with T2DM with normal CRP. T2DM, type III diabetes mellitus; CRP, C-reactive protein; FPG, fasting plasma glucose; PPG, postprandial plasma glucose; FPI, fasting plasma insulin; HOMA-IR, homeostasis model assessment for insulin resistance; TG, triglyceride; TC, total cholesterol; HDL-c, high-density lipoprotein cholesterol; LDL-c, low-density lipoprotein cholesterol.
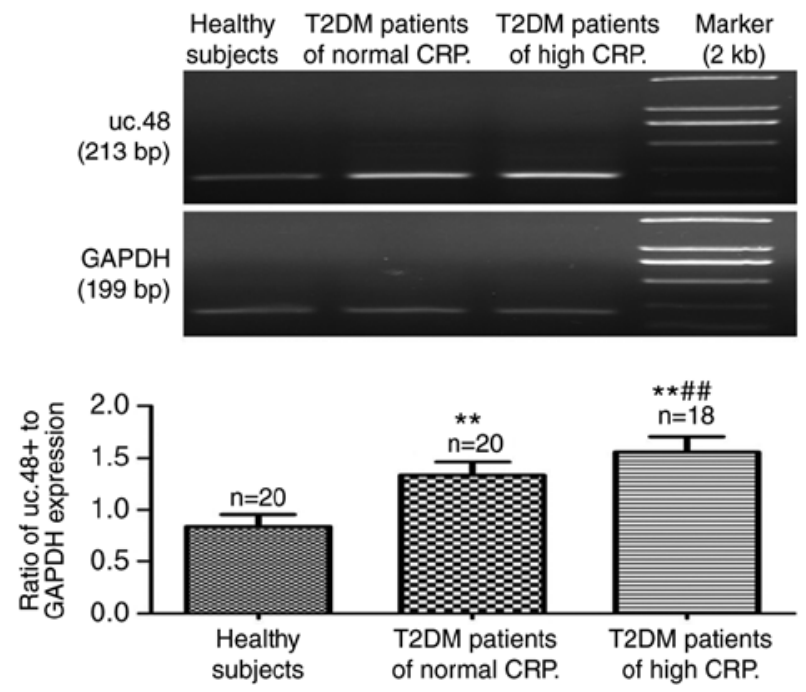

Figure 1. Serum expression of uc.48+ from healthy subjects and patients with T2DM. The serum expression of uc.48+ in patients with T2DM was significantly higher, compared with that in the healthy control subjects $(0.84 \pm 0.12)$. Its expression in patients with T2DM with high CRP levels $(1.56 \pm 0.15)$ was significantly higher, compared with that in patients with T2DM with normal CRP levels (1.33 \pm 0.13$)$. T2DM, type II diabetes mellitus; CRP, C-reactive protein. ${ }^{* *} \mathrm{P}<0.01$ compared with healthy subjects. ${ }^{\# \#} \mathrm{P}<0.01$ compared with T2DM patients of normal CRP.

with T2DM. The anthropometric data and biochemical parameters obtained for the three groups are summarized in Table I. The serum expression of uc.48+ in the patients with T2DM was significantly higher, compared with that in the healthy control subjects $(0.84 \pm 0.12)$, and its expression in patients with T2DM with high CRP levels $(1.56 \pm 0.15)$ was significantly
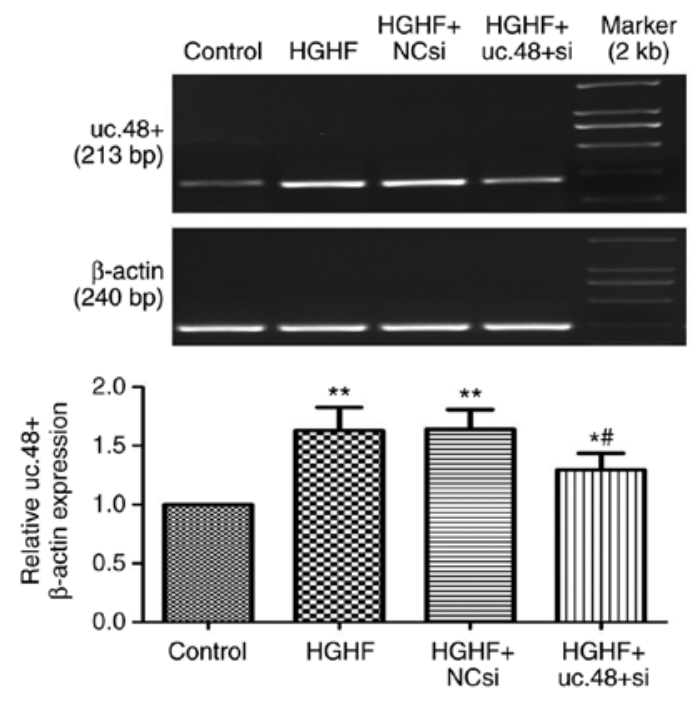

Figure 2. Effects of uc.48+ siRNA on the increased expression of uc.48+ in RAW264.7 macrophages following exposure to high glucose and high FFAs. High glucose and high FFAs significantly elevated the expression of uc.48+ in RAW264.7 macrophages, which was significantly downregulated following treatment with uc.48+ siRNA $(1.30 \pm 0.14)$. No significant difference was found between the HGHF group $(1.63 \pm 0.20)$ and the HGHF+NC siRNA group (1.64 \pm 0.18$)$. siRNA, small interference RNA; FFAs, high plasma free fatty acids; HGHF, high glucose and high FFAs; NC, negative control. ${ }^{*} \mathrm{P}<0.05$ compared with control group, ${ }^{* *} \mathrm{P}<0.01$ compared with control group and ${ }^{\#} \mathrm{P}<0.05$ compared with HGHF group.

higher compared with that in patients with T2DM with normal CRP levels (1.33 \pm 0.13$)$ (Fig. 1).

Effects of uc.48+ siRNA on the increased expression of uc.48+ in RAW264.7 macrophages following exposure to high 

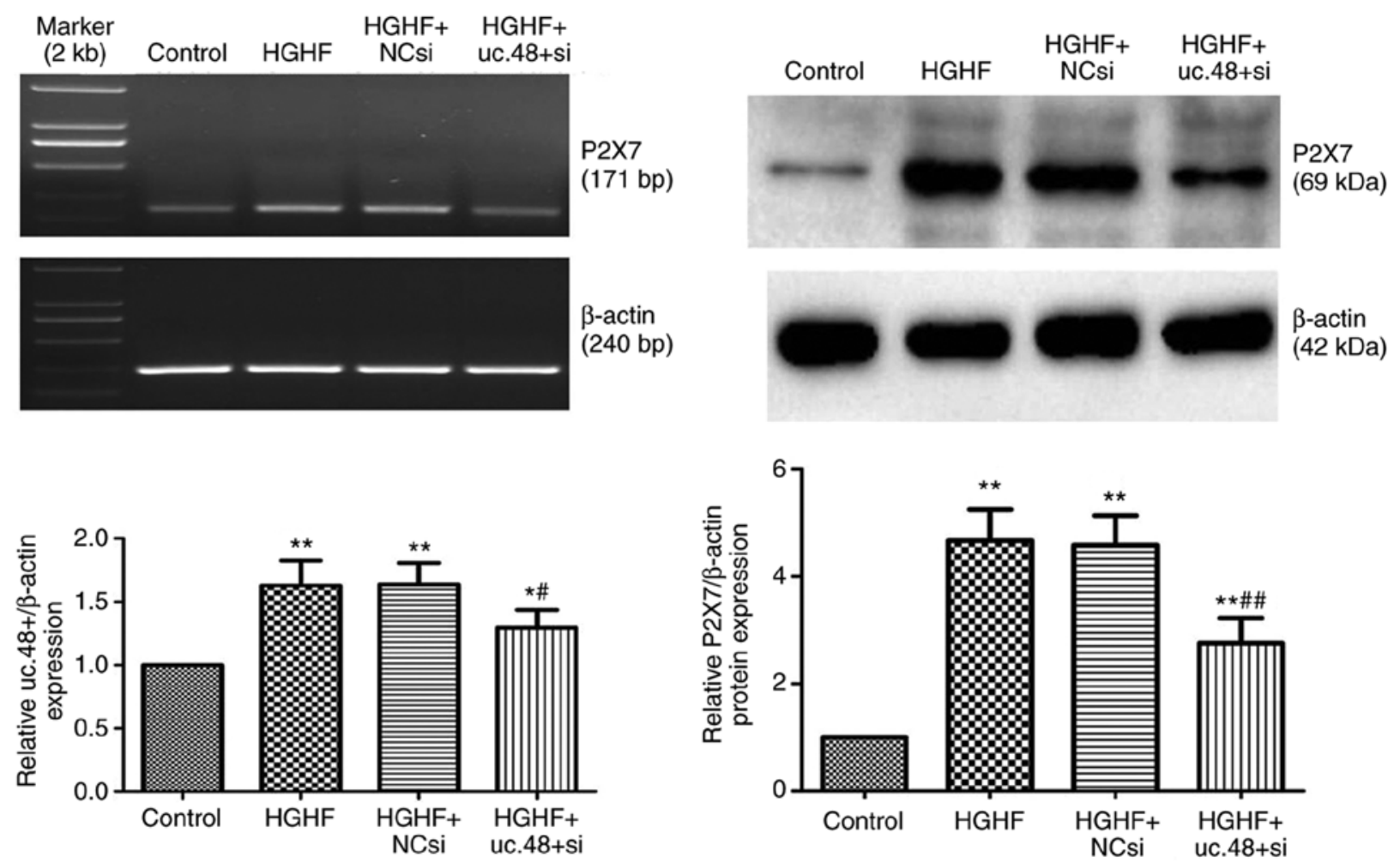

Figure 3. Effects of uc.48+ siRNA on the increased mRNA and protein expression of $\mathrm{P} 2 \mathrm{X}_{7} \mathrm{R}$ in RAW264.7 macrophages following exposure to high glucose and high FFAs. The mRNA (above) and protein (below) levels of $\mathrm{P}_{2} \mathrm{X}_{7} \mathrm{R}$ were significantly decreased in the uc.48+ siRNA group $(1.16 \pm 0.09$ and $2.75 \pm 0.47$, respectively), as determined using reverse transcription-polymerase chain reactionanalysis at $48 \mathrm{~h}$ and western blot analysis at $72 \mathrm{~h}$ following transfection of the RAW264.7 macrophages. No significant difference was found between the HGHF group $(1.42 \pm 0.21$ and $4.66 \pm 0.58$, respectively) and the HGHF+NC siRNA group (1.39 \pm 0.17 and $4.58 \pm 0.55$, respectively). $\mathrm{P} 2 \mathrm{X}_{7} \mathrm{R}, \mathrm{P} 2 \mathrm{X}_{7}$ receptor; siRNA, small interference RNA; NC, negative control; FFAs, high plasma free fatty acids; HGHF, high glucose and high FFAs. ${ }^{~} \mathrm{P}<0.05$ compared with control group, ${ }^{* *} \mathrm{P}<0.01$ compared with control group, ${ }^{\text {"P }}<0.05$ compared with HGHF group and ${ }^{\# \#} \mathrm{P}<0.01$ compared with HGHF group.

glucose and high FFAs. The expression of uc.48+ was significantly downregulated following treatment with uc.48+ siRNA $(1.30 \pm 0.14)$, whereas no significant difference was found between the HGHF group $(1.63 \pm 0.20)$ and the HGHF+NC siRNA group (1.64 \pm 0.18 ) (Fig. 2). The results showed that the siRNA targeting uc.48+ effectively suppressed the expression of uc.48+ in RAW264.7 macrophages.

Effects of uc.48+ siRNA on the increased $m R N A$ and protein expression of $P 2 X_{7} R$ in $R A W 264.7$ macrophages following exposure with high glucose and high FFAs. As shown in Fig. 3, the upregulated mRNA (above) and protein (below) levels of $\mathrm{P} 2 \mathrm{X}_{7} \mathrm{R}$ were markedly decreased following uc.48+ siRNA knockdown by transfection with uc.48+ siRNA $(1.16 \pm 0.09$ and $2.75 \pm 0.47$, respectively), compared with those in the HGHF group (1.42 \pm 0.21 and $4.66 \pm 0.58$, respectively) and HGHF $+\mathrm{NC}$ siRNA group ( $1.39 \pm 0.17$ and $4.58 \pm 0.55$, respectively). No significant difference was found between the HGHF group and the HGHF +NC siRNA group.

$u c .48+$ siRNA can partially reduce the apoptosis and proliferation inhibition of RAW264.7 macrophages induced by exposure of high glucose and high FFAs. The results indicated that the loss of uc.48+ partially reversed the inhibition of proliferation induced by high glucose and high FFAs using the MTS assay (Fig. 4, above). The results also showed that the uc.48+ siRNA significantly decreased the percentage of
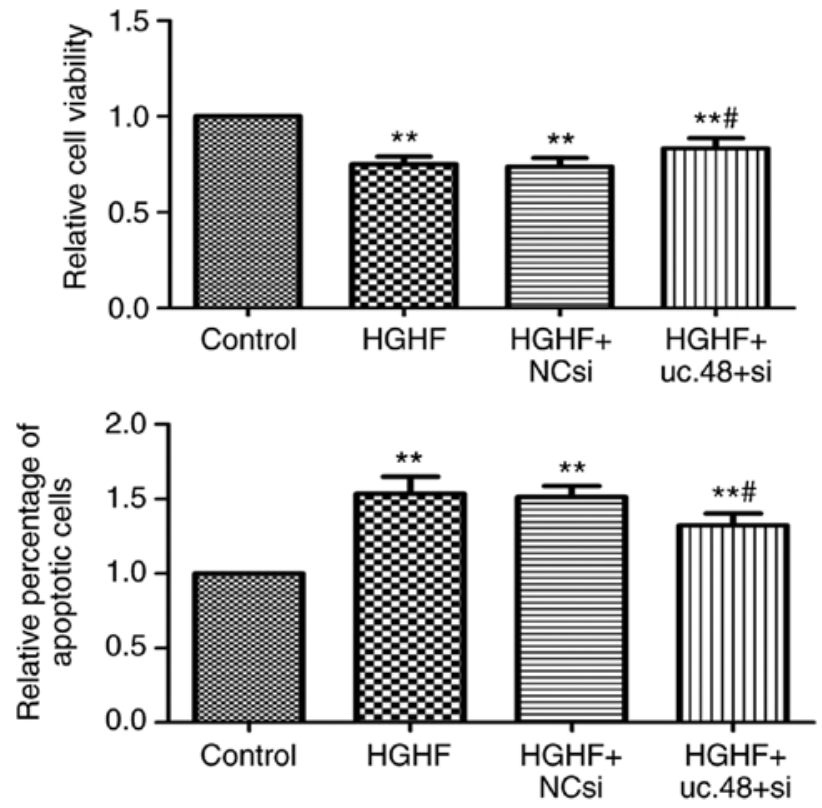

Figure 4. uc.48+ siRNA partially reduces the apoptosis and inhibition of proliferation of RAW264.7 macrophages induced by exposure of high glucose and high FFAs. The loss of uc.48+ partially reduced the inhibition if proliferation induced by high glucose and high FFAs (above). The uc.48+ siRNA significantly decreased the percentage of apoptotic cells following high glucose and high FFA treatment (below). siRNA, small interference RNA; NC, negative control; FFAs, high plasma free fatty acids; HGHF, high glucose and high FFAs. ${ }^{* *} \mathrm{P}<0.01$ compared with control group, ${ }^{\#} \mathrm{P}<0.05$ compared with HGHF group. 


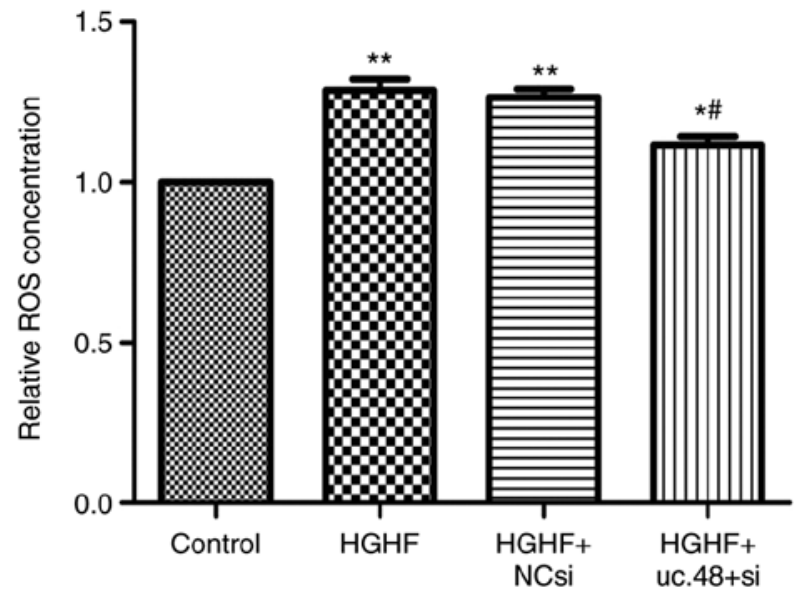

Figure 5. Effects of uc.48+ siRNA on the upregulated levels of ROS in RAW264.7 macrophages following exposure to high glucose and high FFAs. The results showed that ROS was significantly increased in the HGHF group $(1.29 \pm 0.06)$, compared with that in the control group $(1.00 \pm 0.00)$, whereas uc.48+ siRNA $(1.12 \pm 0.05)$ markedly reduced the ROS concentration. ROS, reactive oxygen species; siRNA, small interference RNA; NC, negative control; FFAs, high plasma free fatty acids; HGHF, high glucose and high FFAs. ${ }^{*} \mathrm{P}<0.05$ compared with control group, ${ }^{* *} \mathrm{P}<0.01$ compared with control group and ${ }^{\#} \mathrm{P}<0.05$ compared with HGHF group.

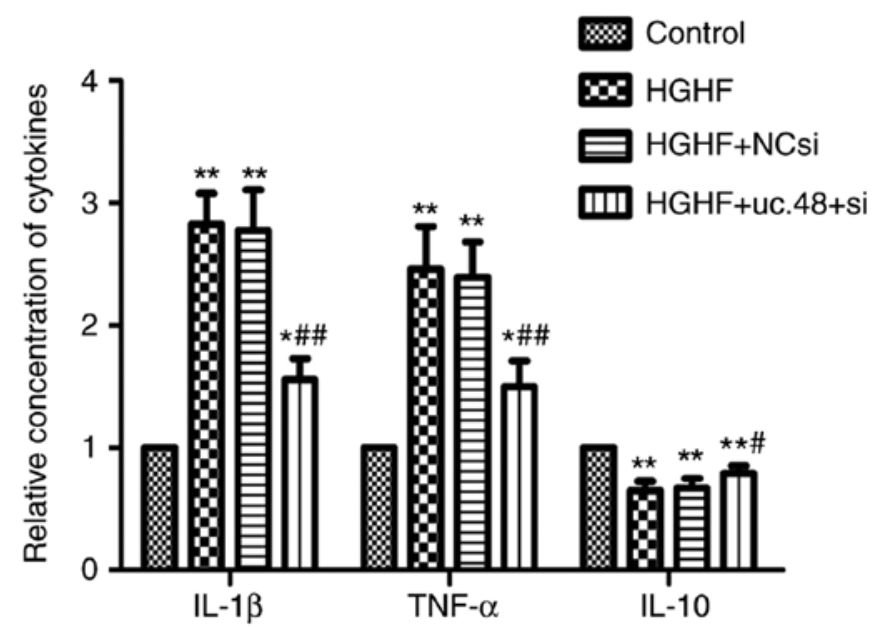

Figure 6. Effects of uc.48+ siRNA on changes of cytokines levels in RAW264.7 macrophages following exposure to high glucose and high FFAs. Cytokine levels in RAW264.7 macrophages, including IL-1 $\beta$, TNF- $\alpha$ and IL-10, were determined by enzyme-linked immunosorbent assays. The results showed that levels of IL-1 $\beta$ and TNF- $\alpha$ were increased in the HGHF group $(2.83 \pm 0.25,2.46 \pm 0.35$, respectively), compared with those in the control $(1.00 \pm 0.00)$, whereas the levels of IL- $1 \beta$ and TNF- $\alpha$ in the uc.48+ group $(1.57 \pm 0.17$ and $1.50 \pm 0.20$, respectively) were markedly decreased. In contrast to the results of TNF- $\alpha$ and IL-1 $\beta$, the level of IL-10 showed the opposite trend. siRNA, small interference RNA; NC, negative control; FFAs, high plasma free fatty acids; HGHF, high glucose and high FFAs; IL, interleukin; TNF- $\alpha$, tumor necrosis factor- $\alpha .{ }^{*} \mathrm{P}<0.05$ compared with control group, ${ }^{* *} \mathrm{P}<0.01$ compared with control group, ${ }^{,} \mathrm{P}<0.05$ compared with HGHF group and ${ }^{\# \#} \mathrm{P}<0.01$ compared with HGHF group.

apoptotic cells following high glucose and high FFA treatment by flow cytometric analysis (Fig. 4, below). Together, these results demonstrated that the uc.48+ siRNA protected the RAW264.7 macrophages from the inhibition of proliferation and induction of apoptosis induced by high glucose and high FFAs.
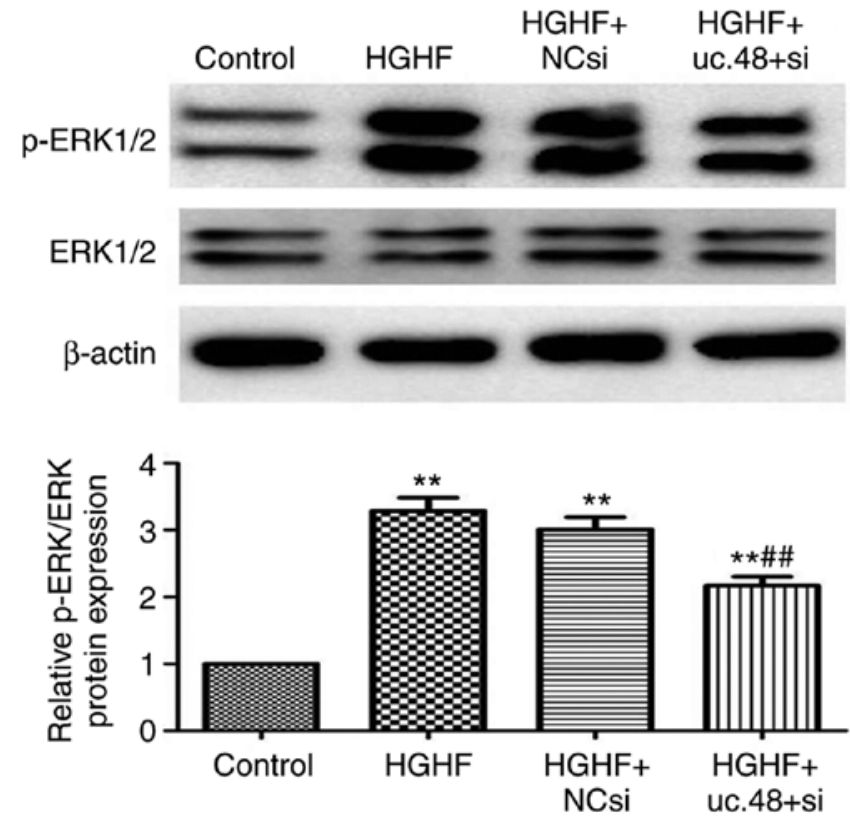

Figure 7. Effects of uc.48+ siRNA on changes in the expression of p-ERK1/2 in RAW264.7 macrophages following exposure to high glucose and high FFAs. High glucose and FFAs (3.28 \pm 0.34$)$ increased the protein levels of p-ERK1/2 in RAW264.7 macrophages. Uc.48+ siRNA (2.17 \pm 0.24$)$ significantly decreased the expression of p-ERK1/2, whereas the scrambled (NC) siRNA (3.01 \pm 0.32$)$ had no significant effect on the expression of p-ERK1/2. ERK1/2, extracellular signal-regulated kinase 1/2; p-ERK1/2, phosphorylated ERK1/2; siRNA, small interference RNA; NC, negative control; FFAs, high plasma free fatty acids; HGHF, high glucose and high FFAs. ${ }^{* *} \mathrm{P}<0.01$ compared with control group and ${ }^{\# \#} \mathrm{P}<0.01$ compared with HGHF group.

Effects of uc.48+ siRNA on the upregulated ROS levels in RAW264.7 macrophages following exposure to high glucose and high FFAs. The results showed that the ROS level was increased in the HGHF group $(1.29 \pm 0.06)$, compared with that in the control $(1.00 \pm 0.00)$, whereas uc. $48+$ siRNA $(1.12 \pm 0.05)$ markedly reduced the ROS concentration (Fig. 5).

Effects of uc.48+ siRNA on changes of cytokines levels in RAW264.7 macrophages following exposure to high glucose

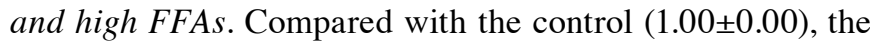
levels of IL-1 $\beta$ and TNF- $\alpha$ were elevated in the cells exposed to HGHF $(2.83 \pm 0.25$ and $2.46 \pm 0.35$, respectively) whereas uc. $48+$ siRNA significantly decreased their levels $(1.57 \pm 0.17$ and $1.50 \pm 0.20$, respectively) (Fig. 6). Compared with the results of IL-1 $\beta$ and TNF- $\alpha$, the level of IL-10 was significantly decreased in the HGHF group $(0.65 \pm 0.08)$, compared with that in the control $(1.00 \pm 0.00)(\mathrm{P}<0.05)$, whereas uc. $48+$ siRNA significantly increased the levels of IL-10

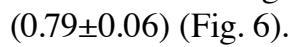

Effects of uc.48+siRNA on changes in the expression of p-ERK1/2 in RAW264.7 macrophages following exposure to high glucose and high FFAs. The levels of p-ERK1/2 and total ERK1/2 were quantified by densitometry, and phosphorylated protein levels were normalized to total protein levels. As shown in Fig. 7, the expression of p-ERK1/2 was significantly increased in the HGHF group (3.28 \pm 0.34$)$, compared with that in the control $(1.00 \pm 0.00)$. The inhibition of uc.48+ with uc. $48+$ siRNA $(2.17 \pm 0.24)$ markedly inhibited the p-ERK1/2 
kinases; scrambled (NC) siRNA (3.01 \pm 0.32$)$ had no significant effect on the expression of p-ERK (Fig. 7).

\section{Discussion}

The events leading to T2DM are complex, however, emerging evidence has shown that various purinergic signaling components may be important regulatory factors $(20,21)$. Our previous preliminary study demonstrated that $\mathrm{P} 2 \mathrm{X}_{7} \mathrm{R}$ in peripheral blood monocytes may be involved in the pathological changes of T2DM, particularly affecting patients with high CRP levels (6). In the previous study, it was found that the expression of uc.48+ in the serum of patients with T2DM and in RAW264.7 macrophages treated with high glucose and high FFAs was significantly increased, compared with the expression in the healthy individuals and control group, respectively. This result suggested that IncRNA uc.48+ was involved in the pathophysiological process of T2DM.

Previous studies have shown that certain lncRNAs may be involved in the pathological processes of diabetes mellitus $(22,23)$. Previous results obtained from rat lncRNA array profiling revealed that the expression of the uc.48+ was significantly increased in the diabetic rat (24). Treatment of RAW264.7 macrophages with uc.48+ siRNA significantly decreased the expression of uc.48+, compared with that in the HGHF group. In the present study, it was found that treatment with uc.48+ siRNA significantly improved the cell survival status through a reduction in apoptosis and reduced proliferation inhibition of RAW264.7 macrophages. Although the present study was limited in that it was only a preliminary study and did not investigate whether which caspases were involved in the apoptotic event, it is possible that uc.48+ siRNA treatment has beneficial effects on RAW264.7 macrophages under diabetic conditions. For future studies, the mechanism of apoptosis requires investigation. Hyperglycemia-induced ROS formation and high FFA-induced oxidative stress may also contribute to the development of T2DM (25). The present study showed that ROS formation was significantly increased when the RAW264.7 macrophages were exposed to high glucose and high FFAs, whereas the levels of ROS were sharply decreased when the cells were treated with uc.48+ siRNA. These findings indicated that uc.48+ siRNA treatment was involved in the regulation of ROS formation.

The upregulation of $\mathrm{P} 2 \mathrm{X}_{7} \mathrm{R}$ is involved in the pathological processes of diabetes mellitus $(15,26)$. The experiments in the present study showed that the mRNA and protein expression of $\mathrm{P} 2 \mathrm{X}_{7} \mathrm{R}$ in RAW264.7 cells were increased due to high glucose and high FFA treatment, compared with those in the controls. This was similar to the results of our preliminary investigation $(6,27)$, which showed that the $\mathrm{P} 2 \mathrm{X}_{7} \mathrm{R}$ may alter the innate immune system contributing to the development of T2DM. The present study was limited by the fact that no binding assays were performed to examine the binding of ATP to $\mathrm{P} 2 \mathrm{X}_{7} \mathrm{R}$. Future investigations aim to improve on this aspect of the pilot study. The present study also revealed that the upregulated expression of mRNA and protein levels of $\mathrm{P}_{2} \mathrm{X}_{7} \mathrm{R}$ in RAW264.7 cells due to high glucose and high FFA treatment were significantly downgraded following uc.48+ siRNA transfection. Taken together, these results suggested that uc.48+ siRNA treatment may ameliorate the pathophysiological process of diabetes mellitus through downregulating $\mathrm{P} 2 \mathrm{X}_{7} \mathrm{R}$ signaling.

Chronic low-grade inflammation is involved in the pathogenesis of T2DM $(4,28)$. It has been reported that the levels of circulating pro-inflammatory cytokines, including IL- $1 \beta$ and TNF- $\alpha$, are increased in the pathological process of T2DM $(29,30)$. IL-1 $\beta$ is essential in orchestrating effective innate and adaptive immune responses among pro-inflammatory cytokines (31). IL-1 $\beta$ enhances the expression of additional pro-inflammatory cytokines, including IL-6 and TNF- $\alpha(32,33)$. The results of the present study showed that the levels of pro-inflammatory cytokines (IL-1 $\beta$ and TNF- $\alpha$ ) were higher in theRAW264.7 cells treated with high FFAs and high glucose, compared with those in the controls, whereas the concentrations of IL-10, an anti-inflammatory cytokine, in the high FFAs and high glucose-treated RAW264.7 cells were lower, compared with those in the controls. When the RAW264.7 macrophages were treated with uc.48+ siRNA, the levels of IL-1 $\beta$ and TNF- $\alpha$ were downregulated and that of IL-10 was upregulated. Therefore, uc.48+ siRNA treatment is likely to be involved in the regulation of cytokine production in monocytes/macrophages in a high FFA and high glucose state.

The activation of $\mathrm{P} 2 \mathrm{X}_{7} \mathrm{R}$ may activate the ERK1/2 signaling pathway to regulate distinct cellular functions $(34,35)$. To determine the possible mechanism of uc.48+ siRNA on $\mathrm{P} 2 \mathrm{X}_{7} \mathrm{R}$, the ERK pathway was examined in the present study. It was observed that the phosphorylation of ERK1/2 was increased on exposure to high FFAs and high glucose, whereas uc.48+ siRNA treatment reversed the upregulated phosphorylation of ERK1/2. These data suggested that uc.48+ siRNA treatment may be associated with intracellular ERK signaling, relieving $\mathrm{P} 2 \mathrm{X}_{7} \mathrm{R}$-mediated inflammatory response in RAW264.7 cells.

Although the role and possible mechanism of uc.48+ in inflammatory pathological damage due to diabetes remains to be elucidated, Wu et al focused on the effect of uc.48+ siRNA in the nervous system (36), whereas the present study focused on the effect of uc.48+ siRNA in the mononuclear phagocyte system. Therefore, these two areas of investigation have different meanings. In addition, although RAW264.7 cells are not the cell-specific cell type for diabetes, further investigations are required to validate macrophages as a cell-type model for diabetes.

In conclusion, the treatment of RAW264.7 cells with high glucose and FFAs increased the expression of uc.48+, which evoked $\mathrm{P} 2 \mathrm{X}_{7} \mathrm{R}$-mediated immune and inflammatory responses through several pathways, including cytokine secretion, ROS formation, and activation of the ERK signaling pathway. uc.48+ siRNA regulated these effects and thus influenced the course and outcome of immune and inflammatory responses mediated by $\mathrm{P} 2 \mathrm{X}_{7} \mathrm{R}$.

\section{Acknowledgements}

The authors would like to thank Professor Shangdong Liang (Department of Physiology, Medical School of Nanchang University, Nanchang, China) for guidance us during the present study. 


\section{Funding}

This study was supported by grants from the National Natural Science Foundation of China (grant no. 81660144).

\section{Availability of data and materials}

The datasets used and/or analysed during the current study are available from the corresponding author on reasonable request.

\section{Authors' contributions}

YN and HW made substantial contributions to the conception and design of the study. YN, HW, FW, MJ and QL made substantial contributions to the acquisition of data. HW drafted the manuscript; YN critically revised the manuscript for important intellectual content. All authors read and approved the manuscript.

\section{Ethics approval and consent to participate}

The present study was approved by the local Ethics Committee of from the First Affiliated Hospital of Nanchang University (approval no. 2018 16), and written informed consent was obtained from each individual.

\section{Consent for publication}

Not applicable.

\section{Competing interests}

The authors declare that they have no competing interests.

\section{References}

1. Czyżewska-Majchrzak Ł, Grzelak T, Kramkowska M Czyżewska $\mathrm{K}$ and Witmanowski $\mathrm{H}$ : The use of low-carbohydrate diet in type 2 diabetes-benefits and risks. Ann Agr Env Med 21: $320-326,2014$

2. Zonszein J, Lombardero M, Ismail-Beigi F, Palumbo P, Foucher S, Groenewoud Y, Cushing G, Wajchenberg B, Genuth S; Bari 2D Study Group: Triglyceride high-density lipoprotein ratios predict glycemia-lowering in response to insulin sensitizing drugs in type 2 diabetes: A post hoc analysis of the BARI 2D. J Diabetes Res 2015: 129891, 2015.

3. Martins AR, Nachbar RT, Gorjao R, Vinolo MA, Festuccia WT, Lambertucci RH, Cury-Boaventura MF, Silveira LR, Curi R and Hirabara SM: Mechanisms underlying skeletal muscle insulin resistance induced by fatty acids: Importance of the mitochondrial function. Lipids Health Dis 11: 30, 2012.

4. Esser N, Legrand-Poels S, Piette J, Scheen AJ and Paquot N: Inflammation as a link between obesity, metabolic syndrome and type 2 diabetes. Diabetes Res Clin Pract 105: 141-150, 2014.

5. Jansen HJ, Stienstra R, van Diepen JA, Hijmans A, van der Laak JA, Vervoort GM and Tack CJ: Start of insulin therapy in patients with type 2 diabetes mellitus promotes the influx of macrophages into subcutaneous adipose tissue. Diabetologia 56: 2573-2581, 2013.

6. Wu H, Nie Y, Xiong H, Liu S, Li G, Huang A, Guo L, Wang S, Xue $\mathrm{Y}, \mathrm{Wu} \mathrm{B}$, et al: $\mathrm{P} 2 \mathrm{X} 7$ receptor expression in peripheral blood monocytes is correlated with plasma $C$-reactive protein and cytokine levels in patients with type 2 diabetes mellitus: A preliminary report. Inflammation 38: 2076-2081, 2015.

7. Solini A, Chiozzi P, Morelli A, Adinolfi E, Rizzo R, Baricordi OR and Di Virgilio F: Enhanced P2X7 activity in human fibroblasts from diabetic patients: A possible pathogenetic mechanism for vascular damage in diabetes. Arterioscl Throm Vas 24: 1240-1245, 2004.
8. Stolz M, Klapperstuck M, Kendzierski T, Detro-Dassen S Panning A, Schmalzing G and Markwardt F: Homodimeric anoctamin-1, but not homodimeric anoctamin-6, is activated by calcium increases mediated by the $\mathrm{P} 2 \mathrm{Y} 1$ and $\mathrm{P} 2 \mathrm{X} 7$ receptors. Pflug Arch 467: 2121-2140, 2015.

9. Huang SW, Walker C, Pennock J, Else K, Muller W, Daniels MJ Pellegrini C, Brough D, Lopez-Castejon G and Cruickshank SM: $\mathrm{P} 2 \mathrm{X} 7$ receptor-dependent tuning of gut epithelial responses to infection. Immunol Cell Biol 95: 178-188, 2017.

10. Jiang L, Liu W, Zhu A, Zhang J, Zhou J and Wu C: Transcriptome analysis demonstrate widespread differential expression of long noncoding RNAs involve in Larimichthys crocea immune response. Fish Shellfish Immun 51: 1-8, 2016.

11. Boysen A, Møller-Jensen J, Kallipolitis B, Valentin-Hansen P and Overgaard $\mathrm{M}$ : Translational regulation of gene expression by an anaerobically induced small non-coding RNA in Escherichia coli. J Biol Chem 285: 10690-10702, 2010.

12. Lutz BM, Bekker A and Tao YX: Noncoding RNAs: New players in chronic pain. Anesthesiology 121: 409-417, 2014.

13. Song G, Shen Y, Ruan Z, Li X, Chen Y, Yuan W, Ding X, Zhu L and Qian L: LncRNA-uc.167 influences cell proliferation, apoptosis and differentiation of P19 cells by regulating Mef2c. Gene 590: 97-108, 2016.

14. Bejerano G, Pheasant M, Makunin I, Stephen S, Kent WJ, Mattick JS and Haussler D: Ultraconserved elements in the human genome. Science 304: 1321-1325, 2004

15. Liu C, Wang J, Yuan X, Qian W, Zhang B, Shi M, Xie J, Shen B, $\mathrm{Xu} \mathrm{H}, \mathrm{Hou} \mathrm{Z}$ and Chen $\mathrm{H}$ : Long noncoding RNA uc. 345 promotes tumorigenesis of pancreatic cancer by upregulation of hnRNPL expression. Oncotarget 7: 71556-71566, 2016.

16. Wang S, Xu H, Zou L, Xie J, Wu H, Wu B, Yi Z, Lv Q, Zhang X, Ying $\mathrm{M}$, et al: LncRNA uc.48+ is involved in diabetic neuropathic pain mediated by the $\mathrm{P} 2 \mathrm{X} 3$ receptor in the dorsal root ganglia. Purinerg Signal 12: 139-148, 2016.

17. Lv Q, Xue Y, Li G, Zou L, Zhang X, Ying M, Wang S, Guo L, Gao Y, Li G, et al: Beneficial effects of evodiamine on P2X(4)-mediated inflammatory injury of human umbilical vein endothelial cells due to high glucose. Int Immunopharmacol 28: 1044-1049, 2015.

18. Xu H, Wu B, Jiang F, Xiong S, Zhang B, Li G, Liu S, Gao Y, Xu C, Tu G, et al: High fatty acids modulate P2X(7) expression and IL-6 release via the p38 MAPK pathway in PC12 cells. Brain Res Bull 94: 63-70, 2013.

19. Gao Y, Liu H, Deng L, Zhu G, Xu C, Li G, Liu S, Xie J, Liu J, Kong F, et al: Effect of emodin on neuropathic pain transmission mediated by $\mathrm{P} 2 \mathrm{X} 2 / 3$ receptor of primary sensory neurons. Brain Res Bull 84: 406-413, 2011.

20. Suryadevara S, Ueno M, Tello-Montoliu A, Ferreiro JL, Desai B, Rollini F, Box LC, Zenni M, Guzman LA, Bass TA and Angiolillo DJ: Effects of pioglitazone on platelet P2Y12-mediated signalling in clopidogrel-treated patients with type 2 diabetes mellitus. Thromb Haemostasis 108: 930-936, 2012.

21. Burnstock G and Novak I: Purinergic signalling and diabetes. Purinerg Signal 9: 307-324, 2013.

22. Jaé $N$ and Dimmeler S: Long noncoding RNAs in diabetic retinopathy. Circ Res 116: 1104-1106, 2015.

23. Jiang GJ, Zhang T, An T, Zhao DD, Yang XY, Zhang DW, Zhang Y, Mu QQ, Yu N, Ma XS and Gao SH: Differential expression of long noncoding RNAs between sperm samples from diabetic and non-diabetic mice. PloS One 11: e0154028, 2016.

24. Gao W, Wang ZM, Zhu M, Lian XQ, Zhao H, Zhao D, Yang ZJ, Lu X and Wang LS: Altered long noncoding RNA expression profiles in the myocardium of rats with ischemic heart failure. J Cardiovasc Med (Hagerstown) 16: 473-479, 2015.

25. Younce CW, Wang K and Kolattukudy PE: Hyperglycaemiainduced cardiomyocyte death is mediated via MCP-1 production and induction of a novel zinc-finger protein MCPIP. Cardiovasc Res 87: 665-674, 2010.

26. Glas R, Sauter NS, Schulthess FT, Shu L, Oberholzer J and Maedler K: Purinergic P2X7 receptors regulate secretion of interleukin-1 receptor antagonist and beta cell function and survival. Diabetologia 52: 1579-1588, 2009.

27. Liu S, Zou L, Xie J, Xie W, Wen S, Xie Q, Gao Y, Li G, Zhang C, $\mathrm{Xu}$ C, et al: LncRNA NONRATT021972 siRNA regulates neuropathic pain behaviors in type 2 diabetic rats through the P2X7 receptor in dorsal root ganglia. Mol Brain 9: 44, 2016.

28. Fernández-Real JM and Pickup JC: Innate immunity, insulin resistance and type 2 diabetes. Diabetologia 55: 273-278, 2012 . 
29. Mirza S, Hossain M, Mathews C, Martinez P, Pino P, Gay JL, Rentfro A, McCormick JB and Fisher-Hoch SP: Type 2-diabetes is associated with elevated levels of TNF-alpha, IL-6 and adiponectin and low levels of leptin in a population of Mexican Americans: A cross-sectional study. Cytokine 57: 136-142, 2012.

30. Saraswathi V, Ramnanan CJ, Wilks AW, Desouza CV Eller AA, Murali G, Ramalingam R, Milne GL, Coate KC and Edgerton DS: Impact of hematopoietic cyclooxygenase-1 deficiency on obesity-linked adipose tissue inflammation and metabolic disorders in mice. Metabolism 62: 1673-1685, 2013.

31. Dinarello CA: Immunological and inflammatory functions of the interleukin-1 family. Annu Rev Immunol 27: 519-550, 2009.

32. Ciraci C, Janczy JR, Sutterwala FS and Cassel SL: Control of innate and adaptive immunity by the inflammasome. Microbes Infect 14: 1263-1270, 2012.

33. Dinarello CA: Blocking interleukin-1 $\beta$ in acute and chronic autoinflammatory diseases. J Intern Med 269: 16-28, 2011.
34. Ponnusamy M, Liu N, Gong R, Yan H and Zhuang S: ERK pathway mediates $\mathrm{P} 2 \mathrm{X} 7$ expression and cell death in renal interstitial fibroblasts exposed to necrotic renal epithelial cells. Am J Physiol Renal Physiol 301: F650-F659, 2011.

35. Zanin RF, Bergamin LS, Morrone FB, Coutinho-Silva R, de Souza Wyse AT and Battastini AM: Pathological concentrations of homocysteine increases IL-1 $\beta$ production in macrophages in a P2X7, NF- $\kappa \mathrm{B}$, and erk-dependent manner. Purinerg Signal 11: 463-470, 2015

36. Wu B, Zhang C, Zou L, Ma Y, Huang K, Lv Q, Zhang X, Wang S, Xue Y, Yi Z, et al: LncRNA uc.48+ siRNA improved diabetic sympathetic neuropathy in type 2 diabetic rats mediated by P2X7, receptor in SCG. Auton Neurosci 197: 14-18, 2016. 